\title{
Conjoined twins, right atrial isomerism, and sequential segmental analysis
}

\author{
MARINEZ BARRA ROSSI, JOHN BURN, SIEW YEN HO, GAETANO THIENE, \\ WILLIAM A DEVINE, ROBERT H ANDERSON
}

From the Department of Paediatrics, Cardiothoracic Institute, Brompton Hospital, London; Department of Human Genetics, University of Newcastle upon Tyne; Division of Pathology, Children's Hospital of Pittsburgh, Pittsburgh, Pennsylvania, USA; and Department of Pathology, University of Padua, Padua, Italy

SUMMARY Three cases of twins conjoined across the chest were examined. In one set, one twin showed right atrial isomerism and the other showed the usual atrial arrangement. The other two sets showed the usual atrial arrangement in both twins. The associated cardiac anomalies were diverse, ranging from atrioventricular septal defects to absent atrioventricular connections. Sequential segmental analysis was used successfully in each case to classify the complex cardiac anomalies. The first step was the recognition of the atrial arrangement. This was easily achieved despite the complexity of the intracardiac morphology.

Conjoined twins have a high incidence of cardiac anomalies particularly when, as occurs most frequently, they are joined across the chest. ${ }^{1}$ We report here three sets of conjoined hearts from twins joined at the chest. In the first set, one twin had right atrial isomerism and showed the cardiac anomalies which accompany this atrial arrangement. In the other two sets, both twins had the usual atrial arrangement together with other cardiac anomalies. Our experience emphasises the importance of accurate recognition of atrial arrangement as the first step in sequential segmental analysis and subsequent classification of associated anomalies.

\section{Case reports}

The three sets of twins were all female and all were joined at their thoracic and abdominal regions. Since there were considerable differences in the specific morphology of the various twins, we need to distinguish the individual members of each pair. This is conventionally done by calling them twins $A$ and $B$, as shown in fig 1 . Thus two sets of twins were joined more or less in side by side fashion. This arrangement can be likened to an opened book, the

Requests for reprints to Dr Siew Yen Ho, Department of Paediatrics, The Cardiothoracic Institute, Fulham Road, London SW3 6HP.

Accepted for publication 23 June 1987 junctional line representing the spine of the book and the bodies of each twin the book pages. In such book-leaf fusion the anterior surfaces of the twins can be viewed by the observer and the twin on the observer's left-hand side is called twin B. The third set of twins was fused in a face to face arrangement

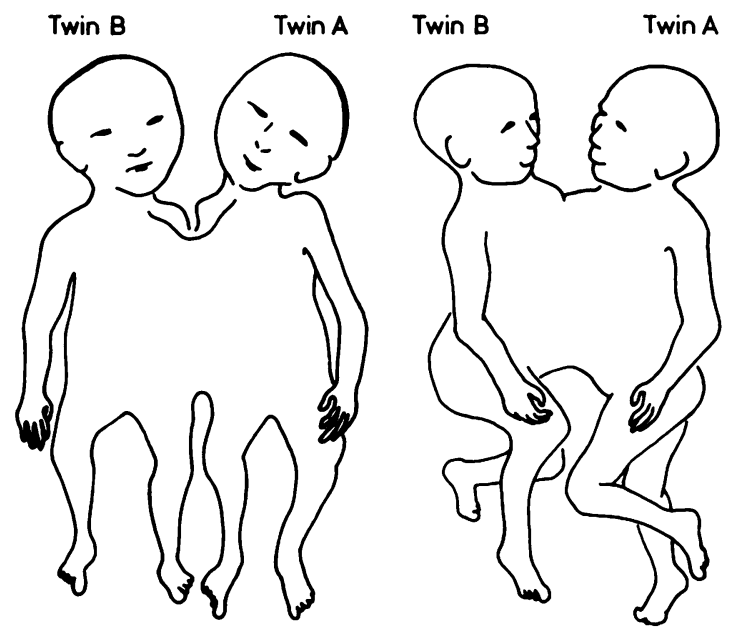

Fig 1 Diagram showing the side by side and face to face arrangement of two sets of thoracopagus twins. The twins are placed in a position that best approximates an open book facing the observer for the designation of $A$ (to the observer's right hand) and $B$ (to the observer's left hand). 
and naming individual members was more difficult, since the pair can be positioned either way up to face the observer. We arbitrarily positioned the pair most closely to approximate the book-leaf arrangement (fig 1). Having designated the twins as " $A$ " and " $B$ " we use the terms "left" and "right" only in respect of the anatomical arrangement in each twin. The hearts and great vessels were examined in all cases and complementary information obtained as and when possible. The table summarises the important cardiac anomalies. The specific details are as follows:

\section{SET 1}

The hearts, which were studied in isolation, were joined at atrial and ventricular levels in book-leaf fashion. There were four atrial appendages. Those of twin B were both of right morphology (right atrial isomerism) as judged by internal and external features (fig 2). The left-sided morphologically right

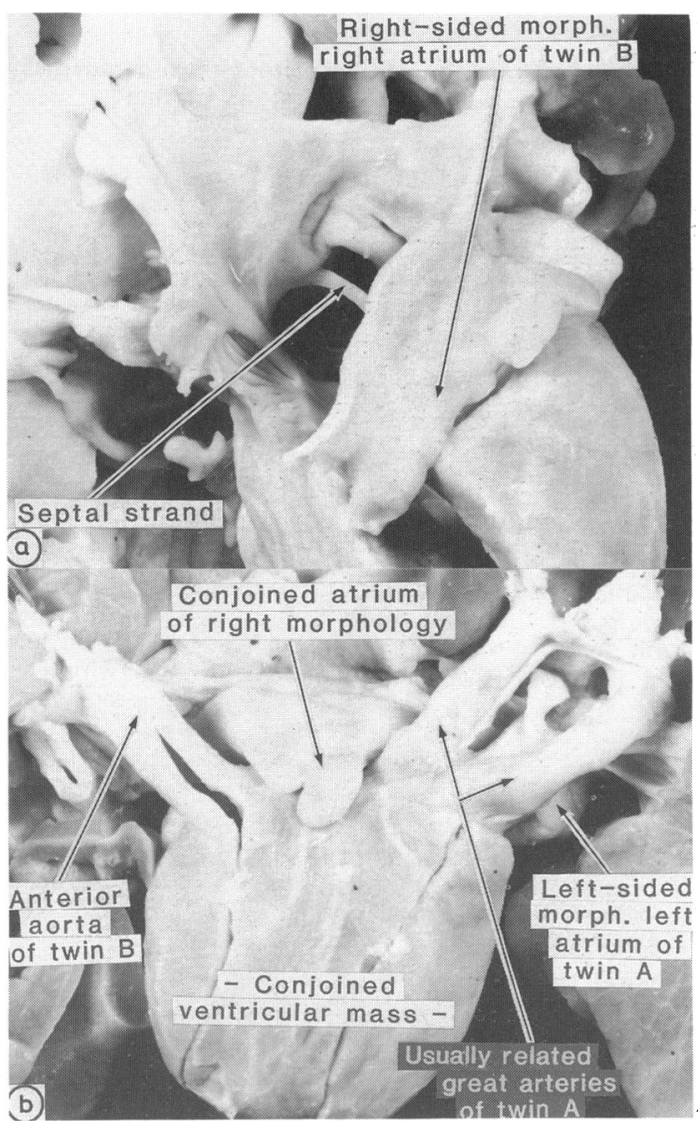

Fig 2 (a) Internal view of the common atrial chamber shared by both twins (set 1), showing the septal strand. (b) Anterior external view of the hearts of set 1 showing the conjoined atrium of right morphology. atrium of twin B was part of a midline atrial chamber common to both twins, the other component being the right-sided morphologically right atrium of twin A. Twin A then had a left-sided atrium of left morphology (usual atrial arrangement). The common atrial chamber was crossed only by a fibrous strand as a remnant of atrial septation. The right side of the common atrium received the common pulmonary vein from twin $B$ while the left side received the systemic veins from twin $B$. The pulmonary venous return from twin A was to the morphologically left atrium.

The four atrial chambers were connected to one ventricular mass through a conjoined atrioventricular junction (fig 3 ). The ventricular mass possessed a right-sided morphologically right ventricle and a left-sided morphologically left ventricle. In addition, there was a rudimentary right ventricle on the left anterior shoulder of this dominant left ventricle that was exclusive to twin $A$. A valve of tricuspid morphology connected the right-sided atrium of twin $B$ to the morphologically right ventricle. This valve overrode and straddled the dominant morphologically left ventricle, the latter chamber being shared by both twins. The right-sided right ventricle supported the subaortic and subpulmonary outflow tracts of twin B. The aorta was anterior and to the right while the pulmonary valve was markedly stenotic. The aortic arch was right-sided with a right-sided arterial duct feeding the conjoined pulmonary arteries. The necropsy report noted that twin B had no spleen. A common atrioventricular valve guarded the right and the left atrioventricular junctions of twin A, together with the junction of the left-sided morphologically right atrium of twin $B$ to the morphologically left ventricle. This ventricle had a large communication with the right ventricle. The latter supported both great arteries (double outlet right ventricle). The outflow to the aorta was obstructed by a muscle band. The aortic arch was left-sided with a left-sided arterial duct and a paraductal coarctation.

\section{SET 2}

The hearts, which were studied in isolation, were joined at atrial and ventricular levels in book-leaf fashion. There were four atrial appendages. Each twin showed the usual atrial arrangement (fig 4). There were bilateral superior and inferior caval veins. The anterior morphologically right atrium of twin A received all the pulmonary venous drainage from this twin through a common pulmonary vein. The pulmonary veins of twin B were connected to the appropriate anterior morphologically left atrium, again through a common channel.

The anterior morphologically right atrium of twin 
Table Summary of the cardiac aniomalies found in three sets of conjoined twins

\begin{tabular}{|c|c|}
\hline$T$ win $B$ & $T \operatorname{win} A$ \\
\hline $\begin{array}{l}\text { Set 1: } \\
\text { Right atrial isomerism } \\
\text { Ambiguous atrioventricular connection } \\
\text { Right-hand topology } \\
\text { Double outlet right ventricle } \\
\text { Totally anomalous pulmonary venous connection }\end{array}$ & $\begin{array}{l}\text { Set 1: } \\
\text { Usual atrial arrangement } \\
\text { Double inlet left ventricle } \\
\text { Double outlet right ventricle }\end{array}$ \\
\hline $\begin{array}{l}\text { Set 2: } \\
\text { Usual atrial arrangement } \\
\text { Concordant atrioventricular connection } \\
\text { Concordant ventriculoarterial connection } \\
\text { Atrioventricular septal defect }\end{array}$ & $\begin{array}{l}\text { Set 2: } \\
\text { Usual atrial arrangement } \\
\text { Absent left atrioventricular connection } \\
\text { Anterior left-sided rudimentary right ventricle } \\
\text { Discordant ventriculoarterial connection } \\
\text { Totally anomalous pulmonary venous connection }\end{array}$ \\
\hline $\begin{array}{l}\text { Set 3: } \\
\text { Usual atrial arrangement } \\
\text { Concordant atrioventricular connection } \\
\text { Concordant ventriculoarterial connection } \\
\text { Totally anomalous pulmonary venous connection }\end{array}$ & $\begin{array}{l}\text { Set 3: } \\
\text { Usual atrial arrangement } \\
\text { Absent right atrioventricular connection } \\
\text { Anterior right-sided rudimentary right ventricle } \\
\text { Discordant ventriculoarterial connection } \\
\text { Totally anomalous pulmonary venous connection }\end{array}$ \\
\hline
\end{tabular}

A was connected to a morphologically left ventricle (fig 5) through a slightly dysplastic atrioventricular valve. This left ventricle supported the pulmonary trunk (discordant ventriculoarterial connection). The posterior morphologically left atrium was small with a complete muscular floor (absent left atrioventricular connection) and communicated with the right atrium through an oval fossa defect. An anterosuperior and left-sided rudimentary right ventricle supported the aorta which was left-sided and posterior. There was a left aortic arch with a patent left arterial duct and a retro-oesophageal

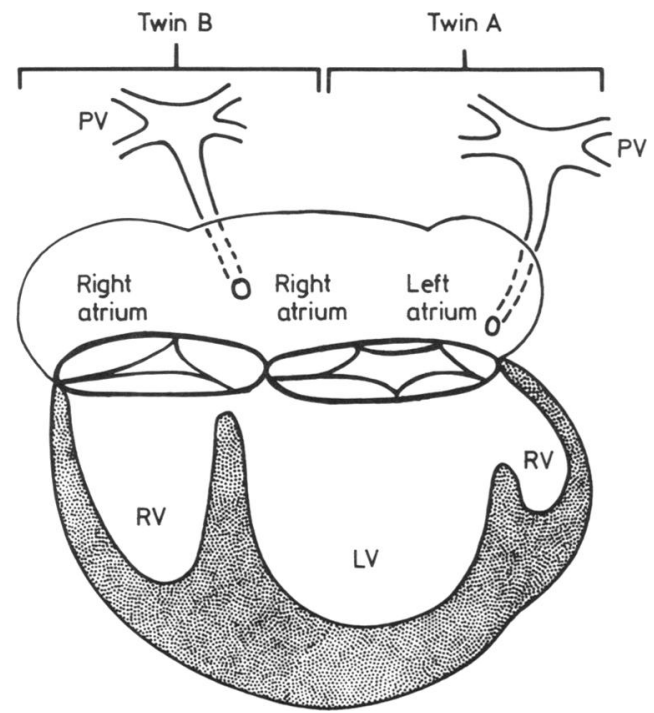

Fig 3 Diagram showing the conjoined atrioventricular junction of set $1 . L V$, left ventricle; $R V$, right ventricle.

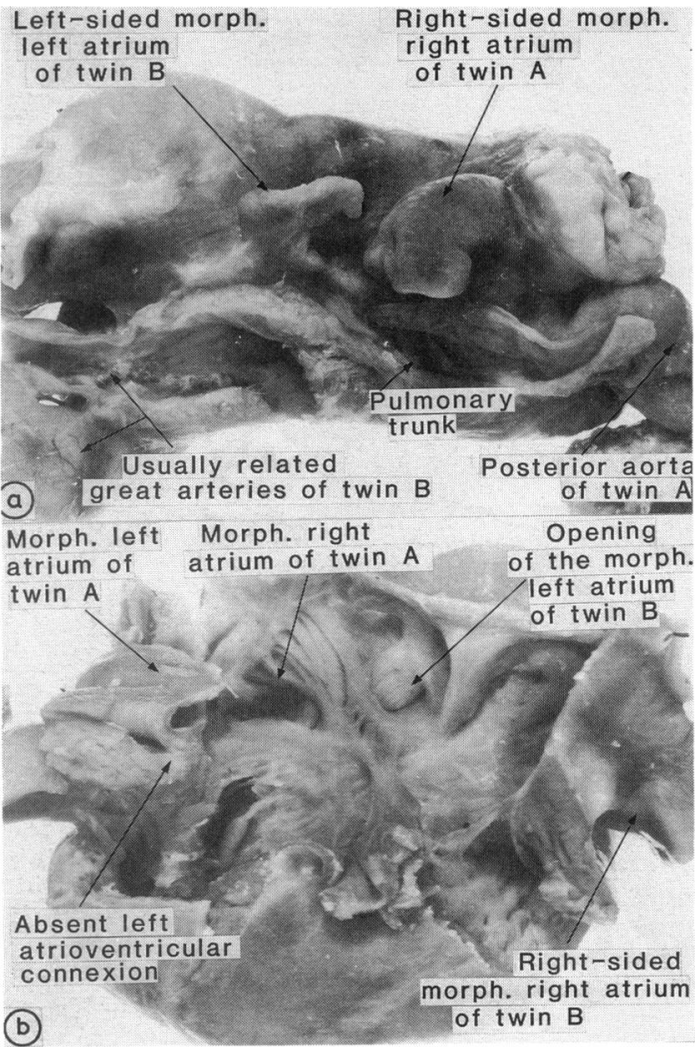

Fig 4 (a) Anterosuperior view of the hearts of set 2 showing the morphologically left atrium of twin $B$, morphologically right atrium of twin $A$, and the great arteries of both twins. (b) Internal view of atria from behind. 


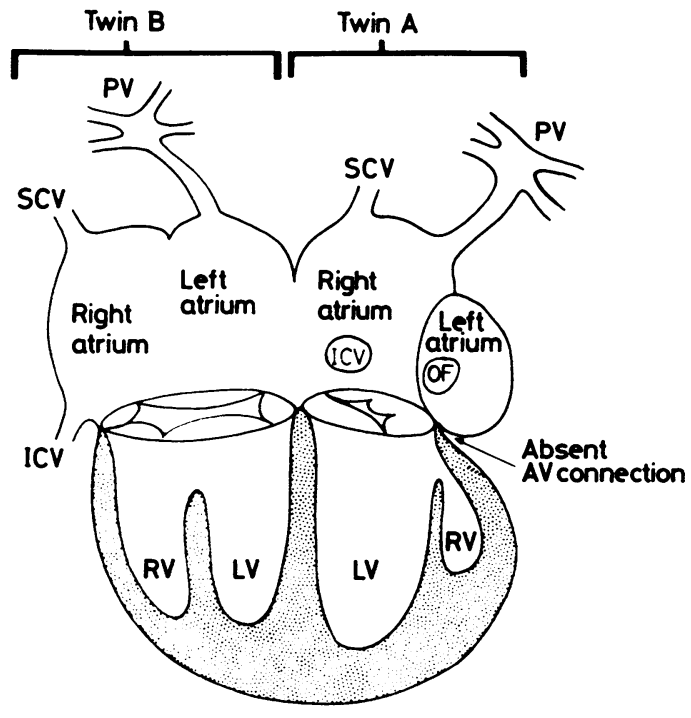

Fig 5 Diagrammatic representation of the hearts of set 2. $I C V$, inferior caval vein; $L V$, left ventricle; $O F$, oval fossa; $P V$, pulmonary vein; $R V$, right ventricle; $S C V$, superior caval vein.

right subclavian artery. The proximal part of the left pulmonary artery was hypoplastic.

Twin B had a concordant atrioventricular connection with right-hand topology of its ventricular mass. Its atrioventricular junction was guarded by a common valve and there was an atrioventricular septal defect. There was minimal bridging of the superior bridging leaflet (Rastelli type A) and the bare crest of the ventricular septum was visible between the superior and inferior bridging leaflets. The morphologically right ventricle supported the pulmonary trunk and the morphologically left ventricle supported the aorta (concordant ventriculoarterial connection). The aorta was posterior and to the right in relation to the pulmonary trunk, which was dilated (normal relations). Twin A, therefore, had absence of the left-sided atrioventricular connection with the right atrium connected to a dominant left ventricle and a discordant ventriculoarterial connection. Twin B had normal chamber connections but showed an atrioventricular septal defect. The ventricles of both hearts were contained within the matrix of a common ventricular mass.

\section{SET 3}

These twins were positioned face to face and joined across the chest and abdomen (fig 6). The chest walls were contiguous laterally, each side being made up by a common sternum articulating with the ribs of each twin. The lungs of both twins showed the usual

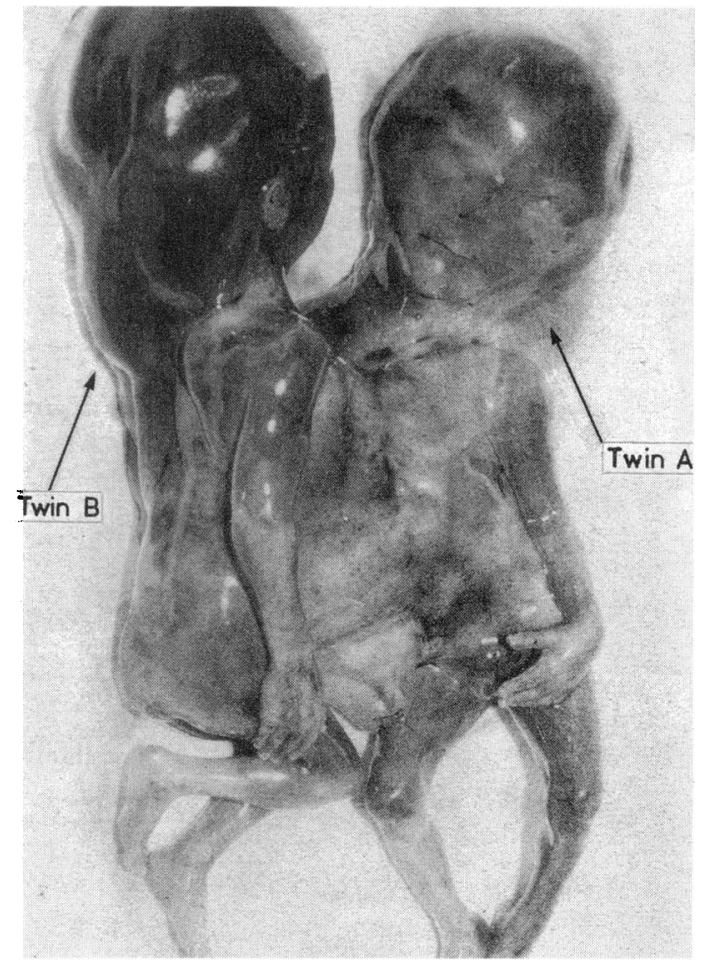

Fig 6 Set of female conjoined twins (set 3) joined across the chest.

lobulation and both twins had a spleen. The liver was common to both, and they also shared a small bowel.

The hearts were joined at atrial and ventricular levels. There were four atrial appendages. Each twin showed the usual atrial arrangement (fig 7). There were bilateral superior caval veins. The left-sided vein received the entire pulmonary venous drainage of twin A and was then connected to the posterior morphologically right atrium of this twin, which also received the entire pulmonary venous return of twin B through the coronary sinus. This morphologically right atrium was small and had a dimple in its muscular floor. There was a defect across the oval fossa which connected to the anterior morphologically left atrium of twin A. The left atrium was connected, through a normal mitral valve, to a morphologically left ventricle which supported the pulmonary trunk. An anterosuperior and rightsided rudimentary right ventricle was carried on the shoulder of the dominant left ventricle and supported an aorta which was anterior and right-sided. The aortic arch then coursed to the left side of twin A. There was a patent left-sided arterial duct.

The anterior morphologically right atrium of twin 


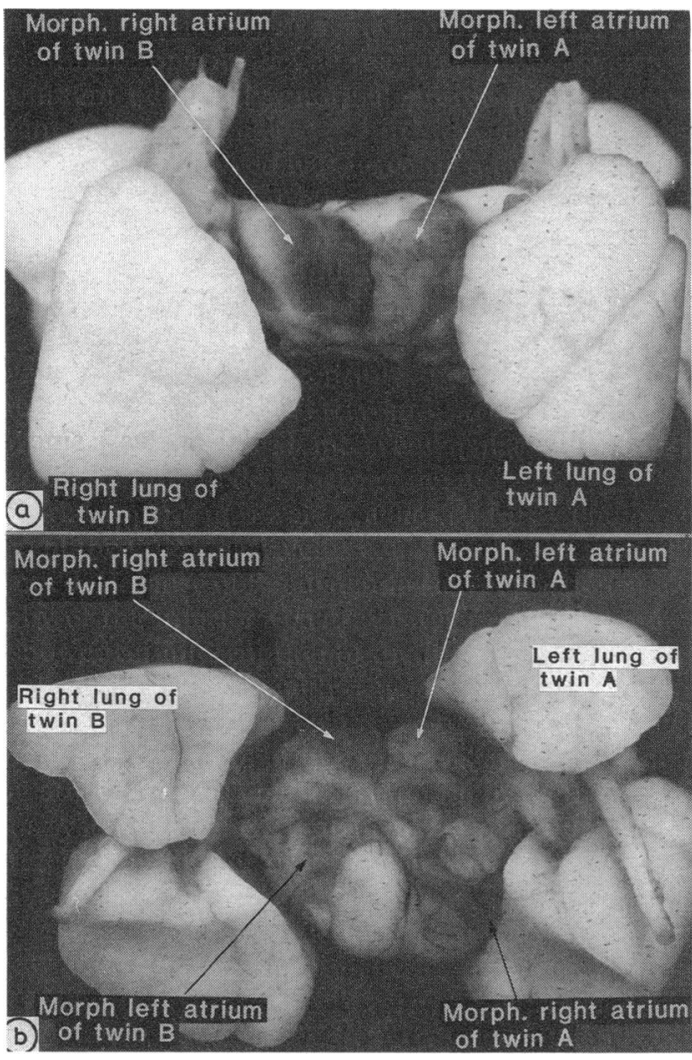

Fig 7 External morphology of the atriums of both twins of set 3 .

$B$ received the right-sided superior caval vein and an inferior caval vein common to both twins. This right atrium connected through an oval fossa defect to the left atrium and through a stenotic tricuspid valve to a morphologically right ventricle. The right ventricle supported the pulmonary trunk. The posterior morphologically left atrium of twin B was connected to a heavily trabeculated morphologically left ventricle which supported the aorta. The aorta was posterior and right-sided. The aortic arch was to the left and there was patency of the arterial duct. The great arteries of twin B were normally related.

Thus there was considerably admixture of the venous connections of both twins, there being totally anomalous pulmonary connections of both to the morphologically right atrium of twin $A$. In terms of cardiac morphology, twin A had tricuspid atresia (absent right atrioventricular connection) with the left atrium connected to a dominant left ventricle and a discordant ventriculoarterial connection. Twin B had normal chamber connections but a ste-

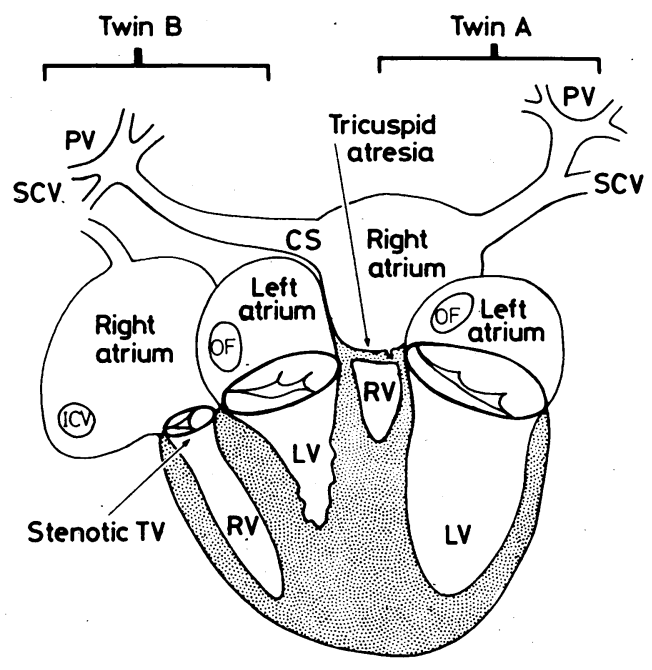

Fig 8 Diagram showing the cardiac anomalies found in the hearts of set 3. Abbreviations as in fig 5.

notic tricuspid valve. The ventricles of both hearts were contained, as in set 2 , within the matrix of a common ventricular mass (fig 8).

\section{Discussion}

The general belief is that conjoined malformations result from incomplete fission of the developing zygote. Conjunction represents the extreme of a time spectrum at the other end of which are "identical" twins with separate placentas (dichorionic monozygotic twins). The developmental separation in the setting of discrete placentas predates the blastocyst stage. The chorion is committed before division in monochorionic monozygotic twins. Monoamniotc twins share an amnion while conjoined twins share some body part, most often in the thoracic region. When joined, the hearts are usually connected at atrial level and may additionally be joined at ventricular level. Usually the venous and arterial connections are distinct.

Isomerism in one of a conjoined twin pair is important in the precise diagnosis of cardiac malformation. It is also pertinent to our understanding of cardiac embryology and to the determination of laterality itself. The important relation between twinning, laterality, and development of the heart and other organs has become clear only recently. Noonan commented on the similarity between the pattern of cardiac malformation in conjoined twins and that seen in isomerism. ${ }^{2}$ Ursell and Wigger subsequently reported right isomerism in one of a set of conjoined twins and drew attention to two other sets. ${ }^{3}$ In their interpretation, they did not discuss 
the relation with laterality. In his classic evaluation of the biases involved in the use of twins as a research tool, Price reviewed the extensive early literature on mirror imagery and lateral inversions. ${ }^{4} \mathrm{He}$ concluded that such disturbance was unlikely to be a major cause of abnormality. Ivemark, in his review of the asplenia syndrome, commented on the abnormal symmetry of the body. ${ }^{5}$ The importance of this feature was brought to the fore by Van Mierop et al. ${ }^{6}$ In particular, Van Mierop et al noted the value of the atrial appendages in the recognition of isomerism. It can be argued that this abnormal symmetry leads to a disturbance of the expected rightward bend of the heart tube (or dextral heart loop) with consequent malformation. This deduction is supported by studies in a particular strain of mouse where disturbance of laterality has an autosomal recessive genetic basis. $^{7}$

Biologists have noted disturbance of organ arrangement in conjoined twins in other species. A good example is the right-sided heart seen in the one half of conjoined trout. ${ }^{8}$ This observation provided part of the evidence in favour of a left/right gradient underlying the determination of laterality in the embryo. ${ }^{9}$ Bringing together these strands of evidence, it may be concluded that the late twinning that produces conjoined individuals is liable to interrupt the "left/right gradient". The result is that the "right" half loses its point of reference and is liable to suffer a disturbance of laterality. This results, in the extreme case, in a twin with two morphologically right sides. A similar explanation may be offered for the right isomerism reported in one of monozygotic twins. ${ }^{1011}$ It is in keeping with the suggestion that the excess of heart defects in monozygotic twin sets is due in part to disturbance of laterality in one set. ${ }^{12}$ In theory, two left sides (left isomerism) could also exist in conjoined twins though this seems not to occur often. One possible example was the conjoined set described by Marin-Padilla et al in which one twin was noted to have two bilobed or "left" lungs. ${ }^{13}$

Our study exemplifies the need for precise identification of atrial morphology. The initial diagnosis of isomerism in one of the twins in set 1 was made by studying the atrial morphology. Subsequent inquiry revealed the absence of spleen in the appropriate twin, the organs being usually arranged in the complementary twin. Atrial morphology was ascertained from constant features, namely the presence (morphologically right atrium) or absence (morphologically left atrium) of the terminal crest together with shape of the appendages. Other criteria such as septal morphology and systemic or pulmonary venous connections are less reliable. Common atrial chambers were present in two of our three cases. There were totally anomalous pulmonary venous connections in four cases within the three sets. Although draining via a common vein, the pulmonary veins were connected to the morphologically left atrium in the remaining two cases. These malformations did not invalidate recognition according to the morphology of the appendages and their junctions with the venous components of the atrial chambers. Accurate diagnosis of the atrial arrangement sets the scene in all instances for successful sequential analysis of the complex cardiac arrangements. Sharing of ventricular chambers has not precluded the use of sequential analysis since each heart can be studied fully in terms of segments. Our study demonstrates the ease of investigating "complex" heart malformations by the use of a systematic approach. Although from a clinical standpoint the shared atrioventricular junctions and/or ventricular musculature in all our sets would have made surgical separation impractical, the same approach would identify those sets which might, in future, be amenable to corrective surgical procedures.

We are grateful to $\mathrm{Mr} \mathbf{P}$ Silverstone, consultant obstetrician in Gateshead, who referred set 3.

MBR was research fellow at the Department of Paediatrics, Cardiothoracic Institute from "Fundacao Federal de Ciencias Medicas de Porto Alegre" supported by "Coordenacao de Aperfeicoamento do Pessoal de Nivel Superior", Education and Culture Ministry of Brazil. SYH is supported by the British Heart Foundation. RHA is supported by the British Heart Foundation together with the Joseph Levy Foundation.

\section{References}

1 Benirschke K, Temple WW, Bloor CM. Conjoined twins: nosology and congenital malformations. In: Birth defects: original series, volume $X I V$, number $6 A$. New York: Alan R Liss for The National Foundation, 1978:170-92.

2 Noonan JA. Twins, conjoined twins and cardiac defects. Am J Dis Child 1978;132:17-8.

3 Ursell PC, Wigger HJ. Asplenia syndrome in conjoined twins: a case report. Teratology 1983;27:301-4.

4 Price B. Primary biases in twin studies. A review of prenatal and natal difference-producing factors in monozygotic pairs. Am J Hum Genet 1950;2: 293-352.

5 Ivemark BI. Implications of agenesis of the spleen on the pathogenesis of conotruncus anomalies in childhood. An analysis of the heart; malformations in the splenic agenesis syndrome, with 14 new cases. Acta Paediatr Scand 1955;44(suppl 104):1-110. 
6 Van Mierop LHS, Gessner IH, Schiebler GL. Asplenia and polysplenia syndromes. In: Birth defects: original article series volume VIII, number 5 . Baltimore: Williams and Wilkins for the National Foundation, 1972:36-44.

7 Layton WM, Manasek FJ. Cardiac looping in early iv embryos. In: Van Praagh R, Takao A, eds. Etiology and morphogenesis of congenital heart disease. Mount Kisco, New York: Futura Publishing Company, 1980:109-26.

8 Neville AC. Animal asymmetry. In: Studies in biology. London: Edward Arnold, 1976:67.

9 Corballis MC, Morgan MJ. On the biological basis of human laterality. Evidence of a maturational left to right gradient. Behavioural and Brain Sciences 1978;2:261-3.

10 Schinzel A, Smith D, Miller J. Monozygotic twinning and structural defects. J Pediatr 1979;95:921-30.

11 Wilkinson JL, Holt PA, Dickinson DF, Jivani SK. Asplenia syndrome in one of monozygotic twins. Eur J Cardiol 1979;10:301-4.

12 Burn J, Corney G. Congenital heart defects and twinning. Acta Genet Med Gemellol 1984;33:61-9.

13 Marin-Padilla M, Chin AJ, Marin-Padilla TM. Cardiovascular abnormalities in thoracopagus twins. Teratology 1981;23:101-13. 